\title{
Fertility and Childbearing Among American Female Physicians
}

\author{
Natalie Clark Stentz, MD, Kent A. Griffith, MPH, MS, Elena Perkins, BS, \\ Rochelle DeCastro Jones, MS, and Reshma Jagsi, MD, DPhil
}

\begin{abstract}
Background: Female physicians may experience unique challenges regarding fertility and family planning. We sought to determine childbearing patterns and decision-making among American female physicians.

Materials and Methods: In 2012-2013, we surveyed a random sample of 600 female physicians who graduated medical school between 1995 and 2000. Primary outcome measures included fertility and childbearing history, reflections regarding decision-making, perceptions of workplace support, and estimations of childbearing potential. Results: Response rate was $54.5 \%$ (327/600). A majority $(82.0 \%)$ of the sample were parents, $77.4 \%$ had biological children with an average of 2.3 children. Average age at medical school graduation was 27.5 years, at completion of training (completion of medical school, residency, and/or fellowship) was 31.6 years, and at first pregnancy was 30.4 years. Nearly one quarter $(24.1 \%)$ of respondents who had attempted conception were diagnosed with infertility, with an average age at diagnosis of 33.7 years. Among those with infertility, 29.3\% reported diminished ovarian reserve. When asked what they would do differently in retrospect, most respondents $(56.8 \%)$ would do nothing differently regarding fertility/conception/childbearing, $28.6 \%$ would have attempted conception earlier, $17.1 \%$ would have gone into a different specialty, and $7.0 \%$ would have used cryopreservation to extend fertility. Fewer of those whose first pregnancy was in medical school perceived substantial workplace support $(68.2 \%)$ than those whose first pregnancies followed training $(88.6 \%)$.

Conclusions: A substantial proportion of female physicians have faced infertility or have regrets about family planning decisions and career decision-making. Combining a medical career with motherhood continues to pose challenges, meriting further investigation and targeted support.
\end{abstract}

Keywords: childbearing, motherhood, female physicians, family planning, conception, infertility

\section{Introduction}

$\mathbf{P}$ HYSICIANS MAY FACE challenges regarding fertility and family planning, given the demands of medical education that necessitate training well into prime reproductive years. ${ }^{1}$ A progressive decline in fertility with aging is immutable ${ }^{2-7}$ and although the timing of this decline is subject to variability; it generally occurs a decade earlier in women than men. ${ }^{8}$ Therefore, the collision of biologic and professional clocks may be a particularly important issue for many female physicians and may have critical implications for professional advancement and career satisfaction.

Numerous studies have demonstrated an increased incidence of childlessness among highly educated women that is likely multifactorial, related to a combination of developed values, professional pressures, and natural reproductive limitations. ${ }^{9,10}$ Unfortunately, most research regarding female physicians' experiences is now relatively dated. ${ }^{11-20}$ A survey of female physicians who graduated from 1950 to 1989, conducted two decades ago, revealed a mean of 1.55 children (and 1.93 children among those more than age 44) compared with projected fertility rates of 2.04 children in 1993-1994 for the general population; this was attributed to higher contraceptive use to avoid pregnancy or control its timing. ${ }^{19}$ Less is known about the ultimate fertility and childbearing experiences of more recent cohorts of physicians, whose professional training might be expected to provide a somewhat more sophisticated understanding of the biological clock and implications of infertility relative to other educated groups of women, and whose experiences may differ from those who entered the field in an era when women constituted a clear minority within the profession.

The present study was designed to evaluate the experiences of a cross-sectional sample of American female physicians expected to be nearing the end of their fertility and biological childbearing. We sought to determine childbearing patterns with special attention to timing of conception and childbearing, perceptions of workplace support, reflections upon professional and personal decision-making, and general knowledge regarding fertility.

Department of Radiation Oncology, University of Michigan, Ann Arbor, Michigan. 


\section{Materials and Methods}

After institutional review board approval, we surveyed a random sample of 600 female physicians from the American Medical Association Physician (AMA) Masterfile with valid mailing addresses. The AMA Masterfile is the most comprehensive listing of American physicians, not restricted to AMA members alone, and assembled based on educational enrollment records and state licensing sources. We included female physicians who had graduated medical school between 1995 and 2000. Given that the vast majority of medical school graduates range in age from 25 to 35 , this criterion was chosen to select primarily women expected to have recently completed or nearly completed childbearing by the time of the survey. In December 2012, we mailed survey questionnaires to 600 individuals along with $\$ 10$. A follow-up questionnaire was sent to nonrespondents in March 2013.

The questionnaire was designed with a standard iterative design process, after review of the literature and extensive consultation with experts in survey design, women's careers, and fertility. The validity of the items was evaluated in detailed cognitive pretesting. ${ }^{21}$ The ultimate questionnaire included 29 items assessing demographics, fertility and childbearing history, impressions based upon personal experience, and estimations of childbearing potential (Supplementary Data; Supplementary Data are available online at www.liebertpub.com/jwh). Key outcome measures included whether and when respondents had attempted conception, experienced pregnancy, or been diagnosed with infertility. We explored the respondents' retrospective reflections and regrets using an item that asked "if you knew in your 20s everything you know now, would you..."; this was followed by a set of check-all-that-apply options (Supplementary Data). We also evaluated perceptions of magnitude of workplace support during the first pregnancy, as well as the impact of career on childbearing options, and vice versa (with responses to these items dichotomized for analysis as "very much" or "quite a bit" vs. "a little bit" or "not at all"). Finally, we evaluated knowledge and perceptions of fertility by asking "In a 1 year period of unprotected intercourse, what do you believe is the percent chance of any woman becoming pregnant" at ages $30,35,40$, and 45 . Respondents were also asked to estimate the efficacy of fertility treatment in the setting of diminished ovarian reserve and were asked to "imagine a woman who has had issues with infertility related to her age (decreased ovarian reserve), but who has unlimited access to fertility treatment. Among 100 of these women, what number do you believe will deliver a biological child?" Finally, respondents were asked to estimate the average cost of one in vitro fertilization (IVF) treatment in the United States. We also collected information on demographic and work characteristics, including whether the respondent had children, the nature of her specialty (grouped by the investigators as in previous studies), ${ }^{22}$ and whether her medical specialty had a "controllable" lifestyle (grouped by the investigators using a categorization scheme initially defined by Schwartz et al., ${ }^{23}$ and more recently described by Dorsey et al., ${ }^{24}$ as a specialty providing personal time for leisure, family, and vocational pursuits and control of total weekly hours spent on professional responsibilities).

Statistical analyses were conducted using the SAS System, version 9.3 (SAS Institute, Inc., Cary, NC). Categorical and continuous data are summarized by the frequency and percentage and mean and standard deviation, respectively. Significant associations were explored between questions using either the chi-square or Fisher's exact tests for categorical data or the two-sample $t$-test or analysis of variance for continuous data. We explored whether women's retrospective regrets differed by whether their specialty had a controllable lifestyle and by whether they ultimately had children or not. We also evaluated whether women in specialties with controllable versus uncontrollable lifestyles differed in their experiences with respect to conception attempts, history of pregnancy, or career impact on childbearing decisions. For statistical tests, $p$-values at or below $5 \%$ were considered significant.

\section{Results \\ Demographics}

We received 327 questionnaires (54.5\% response rate). Those who responded did not differ significantly in terms of geographic distribution $(p=0.35)$ or year of medical school graduation $(p=0.33)$ from nonrespondents. Respondents were an average age of 43.1 years, with the majority $(66.8 \%)$ Caucasian (Table 1). Average age at medical school graduation was 27.5 years, after which respondents completed an average of 4.2 years of postgraduate training at an average age of 31.6 years (Fig. 1).

A majority $(53.9 \%$ [174/323]) of respondents were employed in specialties caring for women, children, and families (Obstetrics and Gynecology, Pediatrics, or Family Medicine), followed by Medical Specialties (32.2\% [104/323]), Hospital-Based Specialties (9.6\% [31/323]) (including Radiology, Anesthesiology, Emergency Medicine, and Pathology), and Surgical Specialties (4.3\% [14/323]). Most respondents were employed in specialties classified as having an uncontrollable lifestyle rather than a controllable lifestyle (82.7\% [267/323] vs. 17.3\% [56/323], respectively). Nearly all $(99.7 \%$ [324/325]) of the respondents were currently practicing medicine.

\section{Likelihood and timing of pregnancy, conception, and parenthood}

A majority $(80.7 \%$ [259/321]) of respondents had attempted to conceive, $78.6 \%(253 / 322)$ had been pregnant, $77.4 \%(253 / 327)$ had biological children, and $82.0 \%$ (268/ 327) were currently parenting biological or adopted/step/ foster children (Table 1). Those who had biological children had an average of 2.3 children. As shown in Figure 1, average age at first intentionally attempting conception was 30.6 years and average age at first pregnancy was 30.4 years. The $17.9 \%(57 / 318)$ of respondents who were contemplating future pregnancy were significantly younger than those who were not considering future children (age 41.1 vs. 43.5, $p<0.001)$. Respondents considering future pregnancy appeared less likely to already have children, although this difference did not achieve statistical significance (73.7\% [42/ 57] vs. $84.3 \%$ [220/261], $p=0.057)$.

A majority $(85.5 \%$ [212/248]) of responding physicians' first pregnancies were intentional, while $14.5 \%(36 / 248)$ were not. Nearly $15 \%$ (14.8\% [37/250]) of respondents who had been pregnant had terminated at least one pregnancy, at 
TABle 1. Demographics

\begin{tabular}{|c|c|}
\hline Characteristics & $\begin{array}{c}\mathrm{n}(\%) \text { or } \\
\mathrm{n}(S D, \text { range })\end{array}$ \\
\hline Age & $43.1(3.5,34-58)$ \\
\hline \multicolumn{2}{|l|}{ Race } \\
\hline White & $217(66.8)$ \\
\hline Asian/Pacific Islander & 65 (19.9) \\
\hline Hispanic/Latina & $13(4.0)$ \\
\hline Black/African American & $19(5.9)$ \\
\hline Other & $9(2.8)$ \\
\hline Missing & 2 \\
\hline \multicolumn{2}{|l|}{ Specialty group } \\
\hline $\begin{array}{l}\text { Specialty for women, } \\
\text { children, and families }\end{array}$ & $174(53.9)$ \\
\hline Medical specialties & $104(32.2)$ \\
\hline Hospital-based specialties & $31(9.6)$ \\
\hline Surgical specialties & $14(4.3)$ \\
\hline Missing & 4 \\
\hline \multicolumn{2}{|l|}{ Specialty lifestyle } \\
\hline Controllable & $56(17.3)$ \\
\hline Uncontrollable & $267(82.7)$ \\
\hline Missing & 4 \\
\hline \multicolumn{2}{|l|}{ Currently practice medicine } \\
\hline Yes & $324(99.7)$ \\
\hline No & $1(0.3)$ \\
\hline Missing & 2 \\
\hline \multicolumn{2}{|l|}{ Attempted to conceive } \\
\hline Yes & $259(80.7)$ \\
\hline No & $62(19.3)$ \\
\hline Missing & 6 \\
\hline \multicolumn{2}{|c|}{$\begin{array}{l}\text { Diagnosed with infertility (measured only among } \\
\text { those who attempted to conceive, } n=259 \text { ) }\end{array}$} \\
\hline Yes & $60(24.1)$ \\
\hline No & $189(75.9)$ \\
\hline Missing & 10 \\
\hline \multicolumn{2}{|l|}{ Experienced pregnancy } \\
\hline Yes & $253(78.6)$ \\
\hline No & $69(21.4)$ \\
\hline Missing & 5 \\
\hline \multicolumn{2}{|c|}{$\begin{array}{l}\text { Terminated pregnancy (measured only among } \\
\text { those who had been pregnant, } n=253 \text { ) }\end{array}$} \\
\hline Yes & $37(14.8)$ \\
\hline No & $213(85.2)$ \\
\hline Missing & 3 \\
\hline \multicolumn{2}{|l|}{ Has child/children } \\
\hline Yes & $268(82.0)$ \\
\hline Biological & 253 \\
\hline Adopted, step, or foster & 28 \\
\hline $\begin{array}{l}\text { Biological and adopted, } \\
\text { step, or foster }\end{array}$ & 16 \\
\hline No & $59(18.0)$ \\
\hline Missing & 0 \\
\hline \multicolumn{2}{|c|}{$\begin{array}{l}\text { Outcome of first pregnancy (among those } \\
\text { who experienced pregnancy, } n=253 \text { ) }\end{array}$} \\
\hline Term delivery & $197(78.2)$ \\
\hline Preterm delivery & $27(10.7)$ \\
\hline Miscarriage & $18(7.1)$ \\
\hline Termination & $10(4.0)$ \\
\hline Missing & 1 \\
\hline
\end{tabular}

an average age of 24. When asked for factors affecting their decision to terminate, career was the most commonly reported factor, cited by $64.9 \%$ (24/37) of respondents, followed by relationship (51.4\% [19/37]) and financial situation (35.1\% [13/37]).
Overall, $21.0 \%(53 / 252)$ of respondents who tried to conceive reported that it took more than 1 year to conceive their first pregnancy and $6.8 \%(17 / 252)$ reported they were unable to become pregnant. In total, $24.1 \%(60 / 249)$ of respondents who tried to conceive reported being formally diagnosed with infertility (at an average age of 33.7 ) and $21.7 \%$ (13/60) of these were ultimately unable to conceive. Of those with explained infertility, $29.3 \%$ (17/58) of diagnoses were related to age or diminished ovarian reserve, $29.3 \%$ (17/58) to ovulatory dysfunction, and $17.2 \%(10 / 48)$ to male factor infertility. Nearly half $(43.1 \%$ [25/58]) of the respondents with infertility reported being "quite a bit" to "very much" surprised about their infertility diagnosis.

\section{Retrospective reflections and regrets}

When asked what they would do differently if they knew in their 20s what they know now, most respondents $(56.8 \%$ [179/315]) stated they would do nothing differently regarding fertility/conception/childbearing. Nevertheless, a substantial minority (28.6\% [90/315]) indicated that they would have attempted conception earlier and smaller but nontrivial minorities endorsed other regrets. These included $17.1 \%(54 /$ 315 ) who would have gone into a different specialty and $7.0 \%$ (22/315) who would have used cryopreservation to extend their fertility (Fig. 2).

When comparing the retrospective reflections of those who did not have children to those who did, $17.9 \%(10 / 56)$ of those without children indicated that they would have used cryopreservation to extend fertility compared to $4.6 \%$ (12/ $259)$ of those with children $(p=0.0004)$. Those who attempted to conceive and were diagnosed with infertility were less likely to report that they would have done nothing differently $(36.7 \%$ [22/60] vs. $61.6 \%$ [157/255] of all others, $p<0.001)$ and were more likely to indicate that they would have attempted to conceive earlier (53.3\% [32/60] vs. $22.8 \%$ [58/255] of all others, $p<0.001)$ and that they would have utilized cryopreservation $(16.7 \%$ [10/60] vs. $4.7 \%$ [12/255] of all others, $p=0.001)$.

Those in controllable specialties were significantly more likely to indicate that they would have utilized cryopreservation to extend their fertility $(18.2 \%$ [10/55] vs. $4.7 \%$ [12/ 257 ], respectively, $p<0.001)$. Respondents in uncontrollable specialties were significantly more likely to endorse that they would have gone into a different specialty compared to those in controllable specialties $(20.2 \%$ [52/257] vs. $1.8 \%$ [1/55], respectively, $p=0.001)$. There was no significant difference between women in controllable and uncontrollable specialties in outcomes such as attempting conception, history of pregnancy, or career impact on childbearing decisions.

\section{Perceived impact of career on childbearing decisions and workplace support}

Most respondents $(65.3 \%$ [209/320]) reported that their career had influenced their childbearing decisions "quite a bit" to "very much"; most (70.4\% [224/318]) respondents also reported that having children had influenced their career. As shown in Figure 3, when assessing the degree of workplace support at the time of first pregnancy, physicians whose first pregnancy occurred during medical school were significantly less likely to report that the workplace was substantially 
FIG. 1. Reproductive and academic timelines of American female physicians. On average, respondents were 43.1 years of age and had graduated medical school at age 27.5. They completed medical training at an average age of 31.6, after an average of 4.2 years of postgraduate training. Average age at first attempt at conception was 30.6. Average age of first pregnancy was $30.4,7.4$ years older than the general population. ${ }^{26}$ Nearly a quarter $(24.1 \%)$ of respondents were formally diagnosed with infertility at an average age of 33.7 .

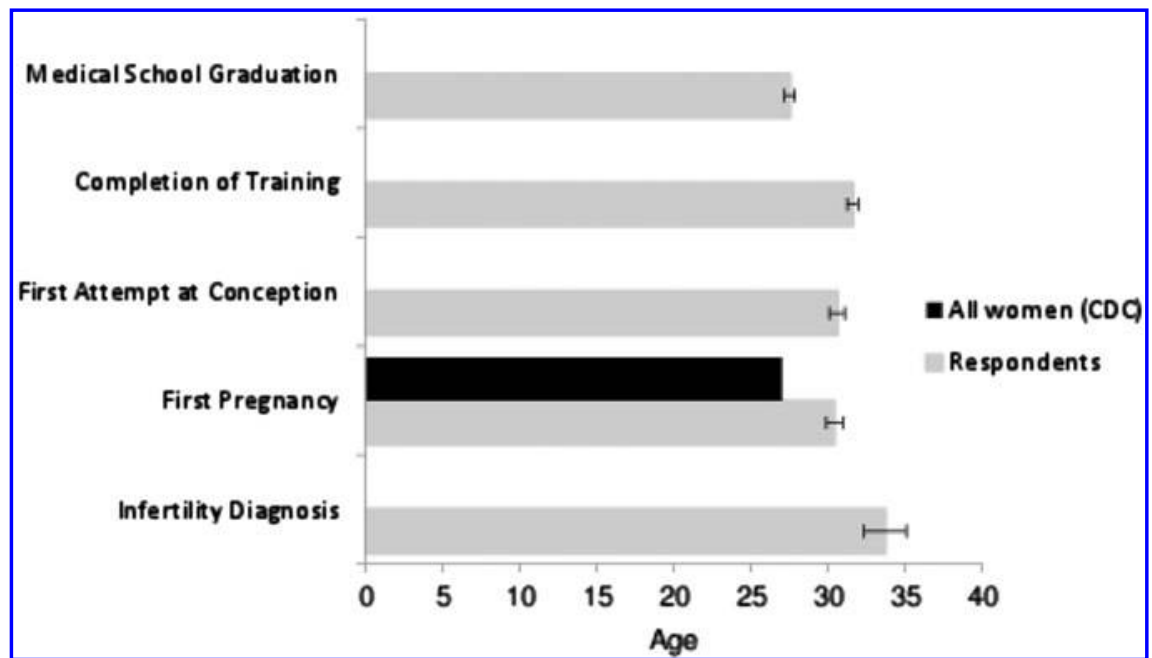

supportive than those whose first pregnancy occurred after completing residency and fellowship training $(p=0.02)$.

\section{Knowledge regarding fertility}

As shown in Figure 4, compared to estimates from landmark studies on age-related fertility, ${ }^{2-7}$ respondents generally tended to underestimate likelihood of conception, particularly at younger ages. The average estimate from respondents regarding the chance of becoming pregnant after a year of unprotected intercourse was $68.3 \%$ at age 30 (95\% CI, 66.1-70.5), 56.1\% at age 35 (95\% CI, 53.8-58.4), 33.1\% at age 40 (95\% CI, 30.8-35.4), and $18.9 \%$ at age 45 (95\% CI, 16.8-21.0). By contrast, when considering a woman with age-related infertility, but unlimited access to fertility treatment, respondents estimated the chance of delivering a biological child to be $33.8 \%$ (95\% CI, 31.1-36.6), which is substantially higher than literature estimates. ${ }^{9}$ Respondents estimated the cost of a single IVF treatment in the United States to be $\$ 18,597$ with high variability in estimates (range $\$ 500-\$ 200,000)$; the U.S. average cost is $\$ 12,400 .^{25}$

\section{Discussion}

In this large national survey, we found that many American female physicians experience challenges regarding fertility and family planning. While prior literature suggests that nearly $85 \%$ of female physicians desire children, ${ }^{11}$ delayed childbearing appears common among American female physicians. The present study found that on average, female physicians have their first child 7.4 years later than the general population. ${ }^{26}$ The majority of physicians in the present study had their first child just before completing residency or fellowship training, consistent with older studies. ${ }^{12,13,27}$ This is not entirely surprising, as medical training is extensive and frequently spans the childbearing years.

Historically, the majority of pregnancies during residency have been planned $(72 \%-77 \%),{ }^{14,15}$ consistent with the current findings $(88.2 \%)$. Physicians who choose pregnancy during training cite desire for family, desire for pregnancy, and concerns regarding fertility. ${ }^{14}$ However, the demands of residency oftentimes conflict with the physical and emotional needs of pregnant women, and an increase in gestational hypertension, placental abruption, preterm labor, and intrauterine growth restriction have been reported in female residents. ${ }^{16}$ Furthermore, the difficulty of combining medical training with parenting may be reflected in the fact that of the respondents who had terminated a pregnancy, career was the most commonly reported deciding factor. While the rate of pregnancy termination reported among the respondent population was under half of that of the general population, ${ }^{28}$ the perceived impact of career demands on pregnancy planning appears important.
FIG. 2. Retrospective reflections and regrets. Respondents were asked to reflect upon their reproductive and academic decision-making. Reassuringly, when asked what they would do differently if they knew in their 20s what they know now, most respondents $(56.8 \%)$ stated they would do nothing differently regarding fertility/ conception/childbearing. Nevertheless, substantial minorities would attempt to conceive earlier, go into a different specialty, or use cryopreservation to extend fertility.

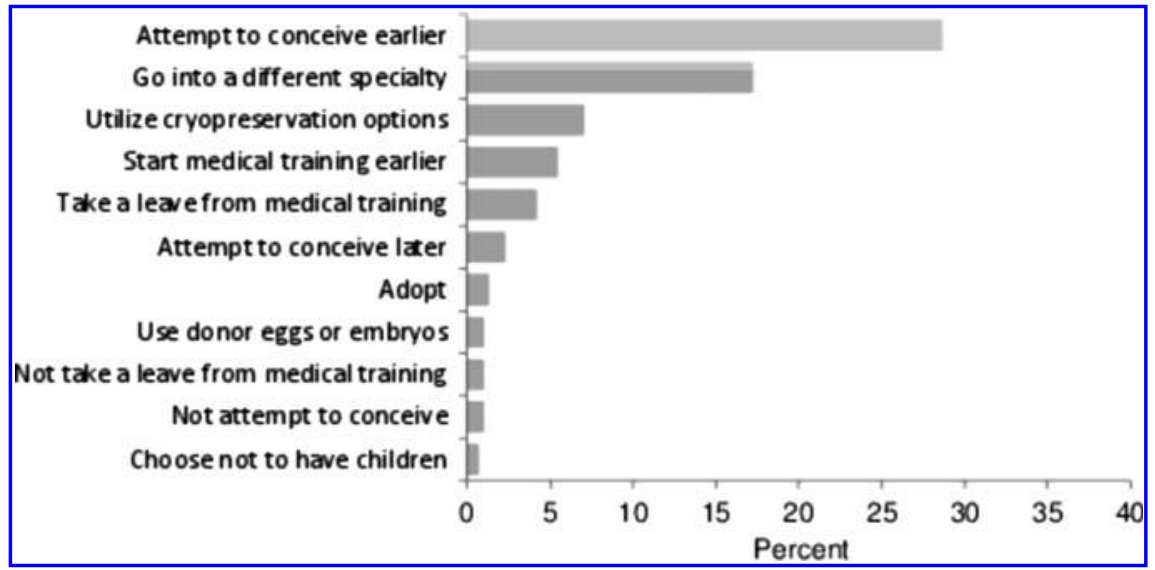




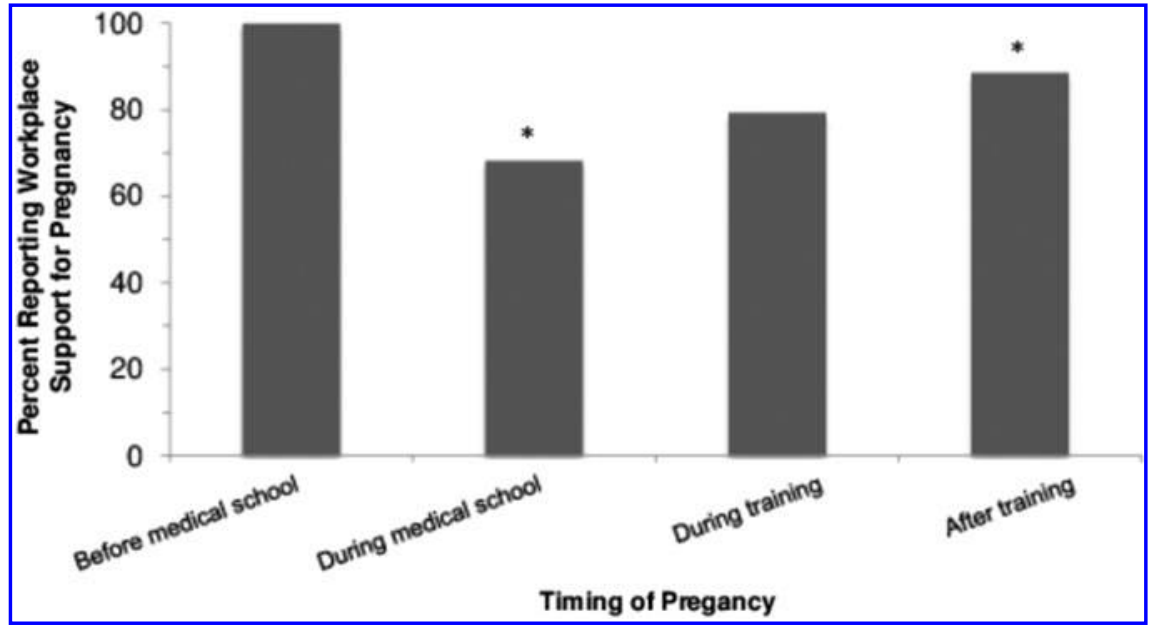

FIG. 3. Workplace support of pregnancy by stage of medical training. Percentages of respondents reporting positive workplace support of pregnancy ("very much" or "quite a bit" supportive) were compared by stage of medical training at time of pregnancy. Those respondents who delivered their first child during medical school were found to have a significantly less supportive work environment than those who delivered after completing medical training $(p=0.02)$. *indicates statistical significance.
When retrospectively examining their reproductive lives, more than a quarter of respondents reported that they would have attempted to have children earlier. However, significant concerns about workplace support of pregnancy during medical training were raised. Those physicians who delivered their first child during medical school were significantly less likely to have perceived substantial workplace support than those delivering after completing medical training $(p=0.02)$. Nevertheless, a majority of respondents at every level of training hearteningly reported that they did perceive workplace support. This suggests positive changes over time: a 1988 national survey ${ }^{12}$ indicated that only $16 \%$ of physicians found their workplace to be supportive of pregnancy and $12 \%$ to be supportive during their child's infancy. Although this may reflect an impact of cultural and legislative changes over time, such as the U.S. Family and Medical Leave Act of 1993, it is important to note that a 2009 survey $^{29}$ reported that $36 \%$ of program directors actively discouraged pregnancy during residency and department chairs viewed pregnancy during residency as a hardship on other residents and an interference on the smooth functioning of a department. Thus, although heartening, it is possible that self-selection effects (by which primarily those women training in supportive programs chose to pursue pregnancy during training) may influence our findings.
Historical literature has also suggested that physicians worry that delaying childbearing will result in infertility or complications related to advanced maternal age. ${ }^{30}$ This is not entirely surprising, as fertility rates decrease substantially after age $35 .^{31,32}$ Data from the most recent 2012 National Survey of Family Growth ${ }^{26}$ indicate that $10.9 \%$ of the general population have impaired fecundity, and women with advanced degrees have an elevated risk of involuntary childlessness related to delayed childbearing. ${ }^{10,26}$ The present study demonstrated a substantial chance of infertility among the American female physician population-a rate twice that of the general population, with nearly a third of that infertility related to age. Reassuringly, those respondents who had biological children had an average of 2.3 children, which is comparable to the national average of 2.1 children according to the 2012 National Survey of Family Growth.

Interestingly, physicians' knowledge regarding fertility was relatively limited. The current sample estimated a $33.8 \%$ chance of conceiving with IVF in the setting of advanced reproductive age, a number several fold higher than the expected chance of conception. ${ }^{9}$ Others have established that nonfertility specialist physicians do not appreciate the rapidity of fertility decline and the lack of effective intervention. ${ }^{33-35}$ Perhaps better information might allow physicians

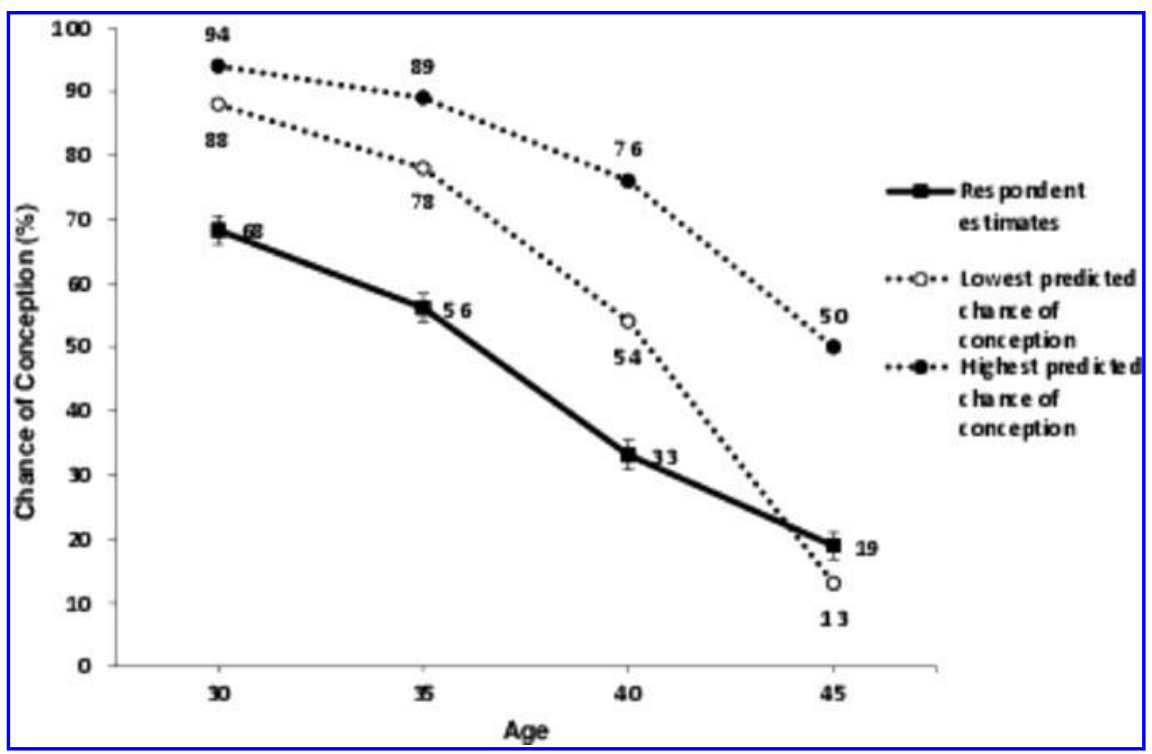

FIG. 4. Physician estimation of fertility at advanced reproductive ages. Physician respondents were asked to estimate the chance of pregnancy at ages $30,35,40$, and 45 . These values were compared to those reported in several landmark studies on agerelated fertility. ${ }^{1-6}$ In general, respondents tended to underestimate likelihood of conception, particularly at younger ages. 
both to make different personal choices and counsel their patients more accurately. Nevertheless, at least when making estimates near the end of their fertile years, this sample of nonfertility specialists was not likely to overestimate fertility at any given age (although they did overestimate the efficacy of IVF in the setting of age-related infertility). It cannot be ignored that individual lives, particularly training physicians' lives, are situated within complex social and cultural circumstances that are not entirely under their control, and lack of knowledge is unlikely to be the sole or even primary driver of the high rates of infertility observed in this population. ${ }^{36-39}$

When reporting on their own experiences with infertility, physicians' reactions differ little from other patients. In a 2013 survey of infertile women more than age 40, Mac Dougall $^{9}$ found that while many were aware of the general effects of age on fertility, nearly $50 \%$ were "shocked" when they discovered the magnitude of their personal risk of agerelated infertility. Similarly, nearly half $(43.1 \%)$ of the physicians in our sample diagnosed with infertility expressed surprise regarding their diagnosis.

In previous studies, most (84\%-94\%) of female physicians report great career satisfaction. ${ }^{12,17,40}$ Prior research indicates that those physicians with more children and less home stress are significantly more likely to be satisfied. ${ }^{18} \mathrm{~A} \mathrm{Ca}-$ nadian study of 419 female surgeons showed that while $50 \%$ reported childbearing had slowed their careers, nearly $88 \%$ would have the same number or more children and an equal number were satisfied with their careers. ${ }^{20}$ In a 1997 study of female urologists, ${ }^{17} 46 \%$ stated that having children had positively affected their career, while $20 \%$ reported a negative impact. Although we did not differentiate positive from negative impact, our findings are consistent in that $65.3 \%$ of respondents reported their career had influenced their childbearing decisions with a similar percentage $(70.4 \%)$ reporting that having children had influenced their career.

This study has a number of strengths, including the carefully selected target population and detailed measures. However, this study also has limitations. Although the questions used were developed with standard techniques of survey design, including cognitive pretesting, and have high face validity, our survey considered sensitive issues. Therefore, it is possible that social desirability, recall, or other biases influenced response. Moreover, those who responded may have been more profoundly affected by infertility or the impact of childbearing on their career. Nevertheless, we received responses from the majority of our target population and reassuringly observed no differences between respondents and nonrespondents on those measures we were able to evaluate in both groups. In addition, although a sizable sample was queried, a larger study might have been able to evaluate for potentially interesting differences within different specialties or other subgroups, and future larger scale research would be useful to allow for greater stratification of results by variables such as specialty, practice type, race, and region and potentially allow for comparisons with women in other high powered careers such as business or law.

\section{Conclusion}

Ultimately, this study attests to many barriers faced by female physicians when combining a medical career with the creation of a family. A substantial proportion of female phy- sicians have faced infertility and regrets about family planning and career decision-making. Combining a medical career with motherhood continues to pose challenges, and further investigation and targeted support, including explicit discussion of these issues during medical education, are critical.

\section{Acknowledgments}

N.C.S., K.G., and R.J. had full access to all of the data in the study and take responsibility for the integrity of the data and the accuracy of the data analysis. Funding/Support: American Medical Association Joan F. Giambalvo Award. Ethical Approval: This study was approved by the University of Michigan Institutional Review Board.

\section{Author Disclosure Statement}

No competing financial interests exist.

\section{References}

1. Jagsi R, Tarbell NJ, Weinstein DF. Becoming a doctor, starting a family-leaves of absence from graduate medical education. N Engl J Med 2007;357:1889-1891.

2. Vincent P. La stérilité physiologique des populations. Population 1950;5:45-64.

3. Henry L. Fondements théoriques des mesures de la fécondité naturelle. Rev 1'Institut Int Stat 1953;21:135-151.

4. Pittenger DB. An exponential model of female sterility. Demography 1973;10:113-121.

5. Leridon H. Human Fertility: The Basic Component. Chicago, IL: Chicago University Press, 1977.

6. Trussel J, Wilson C. Sterility in a population with natural fertility. Popul Stud 1985;39:269-286.

7. Menken J, Trussell J, Larsen U. Age and infertility. Science 1986;233:1389-1394.

8. Dunson DB. Changes with age in the level and duration of fertility in the menstrual cycle. Hum Reprod 2002;17: 1399-1403.

9. Mac Dougall K, Beyene Y, Nachtigall RD. Age shock: Misperceptions of the impact of age on fertility before and after IVF in women who conceived after age 40. Hum Reprod 2013;28:350-356.

10. Sobotka T. In pursuit of higher education, do we postpone parenthood too long? Gend Med 2006;3:183-186.

11. Diamond P. The private lives of women doctors. Medica 1984;2:40-45.

12. Sinal S, Weavil P, Camp MG. Survey of women physicians on issues relating to pregnancy during a medical career. J Med Educ 1988;63:531-538.

13. Finch SJ. Pregnancy during residency: A literature review. Acad Med 2003;78:418-428.

14. Phelan ST. Pregnancy during residency: I. The decision "to be or not to be." Obstet Gynecol 1988;72:425-431.

15. Sayres M, Wyshak G, Denterlein G, Apfel R, Shore E, Federman D. Pregnancy during residency. N Engl J Med 1986;314:418-423.

16. Grunebaum A, Minkoff H, Blake D. Pregnancy among obstetricians: a comparison of births before, during, and after residency. Am J Obstet Gynecol 1987;157:79-83.

17. Bradbury CL, King DK, Middleton RG. Female urologists: A growing population. J Urol 1997;157:1854-1856.

18. Bowman MA, Frank E, Allen DI. Women in medicine: Career and Life Management, 3rd ed. New York, NY: Springer, 2002. 
19. Frank E. Contraceptive use by female physicians in the United States. Obstet Gynecol 1999;94:666-671.

20. Mizgala CL, Mackinnon SE, Walters BC, Ferris LE, McNeill IY, Knighton T. Women surgeons. Results of the Canadian Population Study. Ann Surg 1993;218: 37-46.

21. Willis GB. Cognitive Interviewing: A Tool for Improving Questionnaire Design. Thousand Oaks, CA: Sage Publications, 2005.

22. Jagsi R, Griffith KA, Stewart A, Sambuco D, DeCastro R, Ubel PA. Gender differences in the salaries of physician researchers. JAMA 2012;307:2410-2417.

23. Schwartz RW, Haley JV, Williams C., et al. The controllable lifestyle factor and students' attitudes about specialty selection. Acad Med 1990;65:207-210.

24. Dorsey ER, Jarjoura D, Rutecki GW. Influence of controllable lifestyle on recent trends in specialty choice by US medical students. JAMA 2003;290:1173-1178.

25. ASRM, American Society for Reproductive Medicine. Frequently asked questions about infertility: is in vitro fertilization expensive? 1996 - 2016 ASRM, American Society for Reproductive Medicine. Available at: www.asrm.org/detail .aspx?id=3023 Accessed June 21, 2016.

26. Martinez G, Daniels K, Chandra A. Fertility of men and women aged 15-44 years in the United States: National survey of family growth 2006-2010. Natl Health Stat Report 2012;51:1-29.

27. Bickel J. Maternity leave policies for residents: an overview of issues and problems. Acad Med 1989;64:498501.

28. Jones RK, Kavanaugh ML. Changes in abortion rates between 2000 and 2008 and lifetime incidence of abortion. Obstet Gynecol 2011;117:1358-1366.

29. Cole S, Arnold M, Sanderson A, Cupp C. Pregnancy during otolaryngology residency: Experience and recommendations. Am Surg 2009;75:411-415.

30. Roeske NA, Lake K. Role models for women medical students. J Med Educ 1977;52:459-466.

31. Gilbert WM, Nesbitt TS, Danielsen B. Childbearing beyond age 40: Pregnancy outcome in 24,032 cases. Obstet Gynecol 1999;93:9-14.
32. Cleary-Goldman J, Malone FD, Vidaver J, et al. Impact of maternal age on obstetric outcome. Obstet Gynecol 2005; 105:983-990.

33. Hammond KR, Rocconi RP, Steinkampf MP. Perceptions of age and fertility: A survey of reproductive healthcare providers. Fertil Steril 2002;78:S72-S73.

34. Maheshwari A, Porter M, Shetty A, Bhattacharya S. Women's awareness and perceptions of delay in childbearing. Fertil Steril 2008;90:1036-1042.

35. Daniluk JC, Koert E, Cheung A. Childless women's knowledge of fertility and assisted human reproduction: Identifying the gaps. Fertil Steril 2012;97:420-426.

36. Kemkes-Grottenthaler A. Postponing or rejecting parenthood? Results of a survey among female academic professionals. J Biosoc Sci 2003;35:213-226.

37. Hammarberg K, Clarke VE. Reasons for delaying childbearing - a survey of women aged over 35 years seeking assisted reproductive technology. Aust Fam Physician 2005; 34:187-188, 206.

38. Lampic C, Svanberg AS, Karlström P, Tydén T. Fertility awareness, intentions concerning childbearing, and attitudes towards parenthood among female and male academics. Hum Reprod 2006;21:558-564.

39. Cooke A, Mills TA, Lavender T. "Informed and uninformed decision making"-women's reasoning, experiences and perceptions with regard to advanced maternal age and delayed childbearing: A meta-synthesis. Int J Nurs Stud 2010;47:1317-1329.

40. Hamilton AR, Tyson MD, Braga JA, Lerner LB. Childbearing and pregnancy characteristics of female orthopaedic surgons. J Bone Joint Surg Am 2012;94:e77.

Address correspondence to: Reshma Jagsi, MD, DPhil

Department of Radiation Oncology University of Michigan UHB2C490, SPC 5010

1500 East Medical Center Drive Ann Arbor, MI 48109-5010

E-mail: rjagsi@med.umich.edu 
This article has been cited by:

1. Rashmi Kudesia, Elizabeth Chernyak, Beth McAvey. 2017. Low fertility awareness in United States reproductive-aged women and medical trainees: creation and validation of the Fertility \& Infertility Treatment Knowledge Score (FIT-KS). Fertility and Sterility 108:4, 711-717. [Crossref]

2. Amy A. Sarma, Chileshe Nkonde-Price, Martha Gulati, Claire S. Duvernoy, Sandra J. Lewis, Malissa J. Wood. 2017. Cardiovascular Medicine and Society. Journal of the American College of Cardiology 69:1, 92-101. [Crossref]

3. Steven Hertler. 2016. The Biologically-Based Bias of Personality Disorder Diagnosis. Frontiers in Psychology 7. . [Crossref] 